\title{
Bacillus lentus
}

National Cancer Institute

\section{Source}

National Cancer Institute. Bacillus lentus. NCI Thesaurus. Code C86162.

A species of strictly aerobic Gram-positive, rod shaped bacteria assigned to the phylum Firmicutes. This species is motile, spore forming, catalase positive, urease positive, indole negative, produces hydrogen sulfide, reduces nitrate, and hydrolyzes starch and esculin but not casein or gelatin. B lentus is found in soil, marine waters and sediments and is resistant to nalidixic acid and streptomycin and utilized in the biotechnology industry as a sources of alkaline proteases. 